\title{
Epidemiologic study of children hospitalized with addictive substance intoxication
}

\author{
Farnaz Jelodarzadeh'1, Mehran Hakimzadeh², Farkhondeh Jamshidi ${ }^{3}$ \\ 'Student Research Committee, Ahvaz Jundishapur University of Medical Sciences, Ahvaz, Iran \\ 2Department of Pediatrics, School of Medicine, Abouzar Hospital , Ahvaz Jundishapur University of Medical Sciences, Ahvaz, \\ Iran \\ ${ }^{3}$ Social Determinants of Health Research Center, Department of Forensic Medicine, School of Medicine, Ahvaz Jundishapur \\ University of Medical Sciences, Ahvaz, Iran
}

\section{ABSTRACT}

Introduction: Today, with the increasing prevalence of drug addiction in society, the number of children admitted to pediatric hospitals due to intoxication is increasing. The aim of this study was to evaluate the epidemiology of children hospitalized with narcotic drug intoxication.

Material and methods: It was retrospective study, the records of 300 children under 14 years (including 179 boys and 114 girls) were evaluated who were admitted to Ahvaz Abuzar and Razi hospitals following intoxication with a variety of addictive substances (opium, methadone, heroin, etc.) in 2011-2016. Demographic data, patient records, poisoning information, paraclinical and treatment information and plans were recorded.

Results: Most common causes of poisoning were Methadone 40.3\%, novan (a type of sleeping Medicin) 32\%, and opium $8.7 \%$. The most common symptoms among patients were drowsiness $10.3 \%$, decreased level of consciousness $8.3 \%$, fever, seizures and eloquence $7.3 \%$ and patients with asymptomatic were $1.3 \%$. GE infection was the most common underlying disease (1\%), and $96 \%$ of patients did not have an underlying disease. Percentage of of patients hospitalized were $77 \%$ for 1-3 days and 3\% were not hospitalized for reasons such as death. Main treatment plans were Ampul Naloxan (Maximim $10 \mathrm{mg}$ ) + NG Washing 16.3\%, only Ampul Naloxan 9.3\% and Charcol + Sorbitol + Ampul Naloxan + NG Washing 8.3\%. 61\% of patients were discharged with favorable conditions and $30.3 \%$ of patients were discharged with personal consent.

Conclusions: Finding has shown that children aged 0-2 years were the most exposed to poisoning, and that methadone was the most important drug used. Given the risk of dying in poisoned children, it is necessary to prevent such intoxications, which may be deliberate, by formulating laws, while raising awareness.

\section{KEY WORDS:}

pediatric, epidemiology, intoxication, narcotic drugs.

\section{INTRODUCTION}

Poisoning is a serious, important and one of the most common causes of hospital emergency in many countries $[1,2]$. Approximately $70 \%$ of cases of poisoning occur in children, with more than $90 \%$ being accidental [3]. Acute poisoning of children is a common emergency and one of the major causes of child mortality, especially in developing countries [3]. Many studies have been conducted on the causes of poisoning and their prevalence in different parts of the world, the results of which vary according to different regions, cultural characteristics, and time periods [4]. With the increasing prevalence of drug addiction in society, the pattern of poisoning in children has also changed dramatically and the number of children admitted to pediatric hospitals due to poisoning is

\section{ADDRESS FOR CORRESPONDENCE:}

Farkhondeh Jamshidi, Social Determinants of Health Research Center, Department of Forensic Medicine,

School of Medicine, Ahvaz Jundishapur University of Medical Sciences, 6135715751 Ahvaz, Iran,

e-mail: epidemiology2015@gmail.com 
increasing [5-7]. Drugs account for half of all poisoning in children and account for up to $91 \%$ of deaths in children in some parts of Iran $[8,9]$. One of the common causes of drug intoxication in children is the traditional use of opium and its derivatives to relieve pain or calm the restless child [10]. Poisoning with opium and its derivatives can lead to decreased levels of consciousness, coma, apnea, respiratory suppression, and eventually death, and is always a cause of mortality due to poisoning in children [11]. Different types of drugs, including methadone, tramadol, heroin, etc. are used by children in various forms and cause intoxication. The majority of these cases are inadvertent and accidental consumption by children and other cases are related to unaware feeding and child abuse $[12,13]$. Studies show that, like other countries, child poisoning is one of the significant and important problems in the Iranian health system. According to the results of the studies, the prevalence of types of poisoning in children is increasing and drugs are responsible for half of the poisonings and cause a high percentage of child mortality in different parts of Iran $[14,15]$, so that committing suicide is one of the causes of intoxication in adolescent children, which is more common in girls $[16,17]$. Therefore, because of the high importance of recognizing drug poisoning in children, this study comprehensively examined the type and status of opioid and poisoning in children.

\section{MATERIAL AND METHODS}

In this retrospective study, the records of 300 children under 14 years (including 179 boys and 114 girls) were evaluated who were admitted to Abuzar and Razi hospitals of Ahwaz following intoxication with a variety of addictive substances (opium, methadone, heroin, etc.) in 2011-2016. Patients' demographic information (age, gen-

TABLE 1. Frequence of drug abuse in patients

\begin{tabular}{|l|c|c|}
\hline Toxic substance & Number & $\%$ \\
\hline Methadon & 121 & 40.3 \\
\hline Opium & 26 & 8.7 \\
\hline Novam & 32 & 96 \\
\hline Heroin & 6 & 2 \\
\hline Indeterminate consumables & 9 & 3 \\
\hline Cyanide & 1 & 0.3 \\
\hline Tramadol & 13 & 4.3 \\
\hline Crystal & 14 & 4.7 \\
\hline Alcohol & 8 & 2.7 \\
\hline marijuana & 2 & 0.7 \\
\hline Tennel Syrup & 1 & 0.3 \\
\hline No registration & 3 & 1 \\
\hline Total & 300 & 100 \\
\hline
\end{tabular}

der, place of residence, education), patient records (history of illness, previous exposure to addictive substances), information on intoxication (type of intoxication agent, type of intoxication, type of use, amount of use, clinical symptoms after consumption, first symptom after consumption, patient symptoms after hospitalization, organ damage), paraclinical information $[\mathrm{pH}$ (normal range: 7.38-7.46), bicarbonate, blood pressure, $\mathrm{O}_{2}$ (normal range: $80-100 \mathrm{mmHg}$ ) and $\mathrm{CO}_{2}$ pressure (normal range: 35-45 $\mathrm{mmHg}$ ), potassium, sodium, prothrombin time (PT), Partial Tromboplastin Time (PTT) and International normal size Ratio (INR)] and treatment information and plans (time to hospital arrival, hospital stay until first intervention, treatment plan, length of hospital stay, final outcome of patient status, complications with treatment) were recorded in a checklist.

Descriptive statistics including frequency distribution tables of numerical indices were used to analyze the data. Chi-square and independent sample t-tests were used for correlation between variables. All analyses were performed using SPSS 22 software.

\section{RESULTS}

This study was examinedon on 300 patients, 114 (38\%) were girls and 179 (59.7\%) were boys, and the gender was not recorded for 7 cases. The age range of 0 - 2 years was the most abundant age group (62\%) and the age range of 12-14 years had the lowest frequency (2\%). The youngest patient was 1 day old and the oldest patient was 13 years old. Living of population in city and village were $52.3 \% \& 46.7 \%$ respectly and for 3 cases living conditions were not recorded. Most common causes of poisoning were Methadone $40.3 \%$, novan (a type of sleeping Medicin) 32\%, and opium $8.7 \%$. The most common symptoms among patients were drowsiness $10.3 \%$, decreased level of consciousness $8.3 \%$, fever, seizures and eloquence $7.3 \%$ and patients with asymptomatic were $1.3 \%$. GE infection was the most common underlying disease (1\%), and $96 \%$ of patients did not have an underlying disease. Percentage of of patients hospitalized were $77 \%$ for 1-3 days and 3\% were not hospitalized for reasons such as death. Main treatment plans were Ampul Naloxan (maximim 10 mg) + NG Washing 16.3\%, only Ampul Naloxan 9.3\% and Charcol + Sorbitol + Ampul Naloxan + NG Washing $8.3 \% .61 \%$ of patients were discharged with favorable conditions and $30.3 \%$ of patients were discharged with personal consent.

Laboratory indicators of $\mathrm{pH}, \mathrm{PCO}_{2}$, and Blood Suger (BS) did not differ significantly between patients in rural and urban areas $(p=0.616, p=0.082$, and $p=0.635$, respectively; Table 2). Also, $\mathrm{pH}, \mathrm{PCO}_{2}$, and $\mathrm{BS}$ were not significantly different between boys and girls (Table 3 ). The $\mathrm{pH}$ and $\mathrm{PCO}_{2}$ levels did not differ significantly in different age groups ( $p=0.315, p=0.109$, respectively), but the BS level in different age groups was significantly 
different $(p=0.012)$. The age group $0-2$ years with 212.73 had the highest and the age group 3-5 years with 102.85 had the lowest BS level.

$\mathrm{pH}, \mathrm{PCO}_{2}$, and BS levels were not significantly associated with the type of opioid $(p=0.366, p=0.113$, and $p=0.176$, respectively). Also $\mathrm{pH}, \mathrm{PCO}_{2}$, and blood sugar (BS) levels were not significantly associated with the length of hospital stay $(p=0.10, p=0.116$, and 0.66 , respectively; Table 4).

There was no significant relationship between the type of drug-related symptoms and gender $(p=0.096)$. There was no significant relationship between the patient's final recovery status and the type of drug used ( $p=0.884)$. There was no significant relationship between the duration of hospitalization and the type of drug used ( $p=0.921)$. Also, there was no significant difference between urban and rural patients in terms of the type of drug used ( $p=0.648)$. There was a significant difference between girls and boys in terms of the type of drug used $(p=0.001)$. Also, the type of drug used was significantly different between different age groups $(p<0.0001)$.

\section{DISCUSSION}

Today, drug use and stimulant psychosis threaten all human societies as a serious problem [18]. These substances have acute and long-lasting effects on mood, attention, concentration, cognitive and mental functioning, cause reduced appetite, alterations and hallucinations in vision, can impair one's memory, and lead to disruption and growth retardation [19].

In the present study, out of 300 patients, $59.7 \%$ were male (mean age 1 year and 64 days) and 38\% were female (mean age 3 years), which can be attributed to a more specific behavioral pattern and sense of curiosity in boys that results in their tendency to consume unknown substances [20]. Pedan et al. showed that boys are more at risk of unintentional poisoning than girls because of physical activity [21].

TABLE 2. Comparison laboratory parameters of average and place of residence

\begin{tabular}{|c|c|c|c|}
\hline Place of residence & Number & Average & $P$-value \\
\hline \multicolumn{4}{|l|}{$\mathrm{pH}$} \\
\hline Uran & 124 & 9.78 & \multirow[t]{2}{*}{0.36} \\
\hline Rural & 137 & 9.11 & \\
\hline \multicolumn{4}{|l|}{$\mathrm{PCO}_{2}$} \\
\hline Uran & 124 & 37.5 & \multirow[t]{2}{*}{0.94} \\
\hline Rural & 136 & 40.02 & \\
\hline \multicolumn{4}{|l|}{ Blood Suger } \\
\hline Uran & 131 & 224.62 & \multirow[t]{2}{*}{0.70} \\
\hline Rural & 144 & 134.68 & \\
\hline
\end{tabular}

TABLE 3. Comparison laboratory parameters of average sex wise

\begin{tabular}{|c|c|c|c|}
\hline Gender & Number & Average & $P$-value \\
\hline \multicolumn{4}{|l|}{ pH } \\
\hline Male & 101 & 9.52 & \multirow[t]{2}{*}{0.616} \\
\hline Female & 157 & 9.41 & \\
\hline \multicolumn{4}{|l|}{$\mathrm{PCO}_{2}$} \\
\hline Male & 100 & 37.89 & \multirow[t]{2}{*}{0.08} \\
\hline Female & 157 & 39.46 & \\
\hline \multicolumn{4}{|l|}{ Blood Suger } \\
\hline Male & 106 & 134.10 & \multirow[t]{2}{*}{0.63} \\
\hline Female & 166 & 205.71 & \\
\hline
\end{tabular}

TABLE 4. Comparison laboratory parameters of average and type of opioid

\begin{tabular}{|l|c|c|c|c|}
\hline \multirow{2}{*}{ Toxic substance } & \multicolumn{2}{|c|}{$\mathrm{PCO}_{2}$} & $\mathrm{pH}$ & Blood sugar \\
\cline { 2 - 5 } & Number & Average & Average & Average \\
\hline Methadon & 107 & 39.95 & 9.24 & 120.04 \\
\hline Opium & 22 & 40.30 & 7.38 & 122.30 \\
\hline Novam & 85 & 38.54 & 7.34 & 140.72 \\
\hline Heroin & 6 & 23.50 & 42.57 & 2604.40 \\
\hline Indeterminate consumables & 7 & 33.71 & 23.57 & 134.87 \\
\hline Cyanide & 1 & 36 & 7.33 & 68 \\
\hline Tramadol & 12 & 43.55 & 7.34 & 110.23 \\
\hline Crystal & 11 & 34.85 & 7.36 & 127.58 \\
\hline Alcohol & 7 & 34.67 & 7.30 & 617 \\
\hline Marijuana & 1 & 35 & 7.36 & 340 \\
\hline Tennel syrup & 1 & 36.90 & 7.37 & 0.176 \\
\hline$P$-value & & 0.113 & 0.366 & \\
\hline
\end{tabular}


The mean age of the children in this study was 2 years and 44 days. The youngest patient was 1 day old and the oldest patient was 13 years old. In the study of Kadivar et al. on drug intoxication in children in Tehran, the highest age of poisoning was 3.5 years and the lowest was 7 days [7].

In the study of Mansouri et al., $11.4 \%$ of children with intoxication in Tehran were less than 1 year old and 60\% of them were 2-4 years old, while in the study of poisoned children in Ahvaz, $61 \%$ were in the age range of $0-2$, being the most frequent age group [22].

In places like Golestan province, these substances are used to relieve pain or to calm restless children, and given the high percentage of children aged 0-2 in the present study, it can be said that such use is also seen in Khuzestan province [23].

In the present study, intoxication was higher in urban children (52.3\%) compared to rural children (46.7\%). In a study by Nikvarz et al., $45 \%$ of intoxicated children were city resident [24].

Novan was the main cause of intoxication in girls and methadone was the main cause of intoxication in boys and there was a significant relationship between the used substance and gender. Tramadol intoxication was also seen in boys only. This result contradicts the findings of the study by Nikvarz et al., in which no relationship was found between the intoxication factor and gender.

In the present study, methadone ( $74.7 \%$ of cases) was the most important cause of poisoning. Unfortunately, in recent years, emergency referrals and deaths from methadone use are on the rise. The increased use of methadone on the one hand and the failure to take the necessary measures to prevent the poisoning of this dangerous substance in the community, on the other hand, has made it a threat to children. In the study of Mansouri et al., which evaluated the risk of unintentional child intoxication in Shahed Hospital in Tehran, narcotic drug intoxication was the highest prevalence (58.6\%) followed by medical drug intoxication (30\%) [22], also Alotaibi ingestion of small amounts of methadone can lead to death. There are overlaps between toxic and fatal concentrations; careless storage is a common cause of accidental poisoning of children [25]. In Watson studies, patients who had taken long acting opioids such as methadone developed renarcosis up to 2 hours after their arrival to emergency room. Since the half life of naloxone is 60 to 90 minutes, it seems logical to observe patients for signs of recurrent toxicity for at least 2 hours [26].

In the study of Motlagh et al. in Ahvaz, opium was the cause of intoxication in $13.6 \%$ of children. Opium is one of the most common causes of intoxication. On the other hand, the use of novan as a sedative pseudo-narcotic drug with a destructive role on the respiratory system and with $32 \%$ intoxication is a major alarm for the family and society [27].
Drowsiness, decreased level of consciousness, fever, seizures, and delirium were the most prevalent symptoms among patients, respectively. In the study of Allameh et al., the most important complication of methadone intoxication was loss of consciousness, meiosis, delirium, convulsion and respiratory failure [28]. In the study of Besharat et al., the most common clinical symptoms were decreased consciousness and coma, cyanosis and meiosis, respiratory suppression, and seizure, respectively [23]. Nikvarz et al. investigated the causes of intoxication in children in Jiroft city. The results of their study suggested human drugs (36\%), methadone (28\%) and other drugs (13\%) as the most common cause of intoxication, and reported nervous (39\%), respiratory-neurological (16\%), and gastrointestinal-neurological damage (10\%) as the most common injuries, which were less prevalent in the present study [22].

In the present study, $77 \%$ of patients were admitted for 1-3 days. In the study of LoVecchio et al., the mean hospital stay of children with methadone intoxication was 2.2 days [29]. In the present study, 3.3\% of patients died and cardiac arrest accounted for $11.7 \%$ of deaths. In the study of Besharat et al., $6 \%$ of patients died, which was higher than the present study [23].

There was no association between underlying disease and drug use in the present study. In the study of Kadivar et al., acute diarrhea and acute respiratory infection and irritability were the most common causes of prescribing a drug, and this was not observed in the present study [7]. In the study of Mansouri et al., the risk of intoxication in children with a previous history of intoxication was found to be $6.5 \%$.

In the present study, $30.3 \%$ of patients with personal consent and $61 \%$ after appropriate treatment were discharged. In the study of Nikvarz et al., 90\% of children were discharged after appropriate treatment, which is higher than the present study.

The most frequent treatment plan (16.3\%) was Ampul Naloxan + NG washing. Ampul Naloxan and Charcoal + Sorbitol + Amp Naloxan + NG washing were the next ranks with $9.3 \%$ and $8.3 \%$ respectively, but there was no significant relationship between the type of drug used and the treatment plan, probably because of the similar nature of the drugs. In the study of Besharat et al. on drug intoxication in Golestan infants, treatment with Naloxan and oxygen and intravenous fluids were the main treatments.

There was no significant relationship between laboratory parameters including $\mathrm{pH}, \mathrm{PCO}_{2}$, and $\mathrm{BS}$ with sex and drug type. Laboratory indices of $\mathrm{pH}$ and $\mathrm{PCO}_{2}$ were not significantly different in various age ranges, but BS index was highest in the age group of 0-2 years and lowest in the age group 3-5 years and there was a negative correlation between these two parameters.

\section{CONCLUSIONS}

Results showed that children aged 0-2 years were the most exposed to drug intoxication and methadone 
was the major cause of intoxication. Given the risk of dying of drug-poisoned children, it is essential that families, physicians, and health care personnel in the country have sufficient awareness of the dangerous effects of these drugs. It should also be noted that children who are drug addicts and children exposed to these substances are severely addicted during their adolescence. This provides the basis for their greater propensity to commit a crime, physical assault and rape, car accidents, dropping out of school, absenteeism and school-related illnesses and sexually transmitted diseases. Therefore, it is necessary to prevent such intoxications, which may be deliberate, by formulating laws, while raising awareness.

\section{ACKNOWLEDGMENT}

This reseach is part of General Physition thesis has don by Farnaz Jolodarzadeh and was supported from Deputy of Research in Ahvaz Jundishapur University of Medical Sciences (B-95/005).

\section{DISCLOSURE}

The authors declare no conflict of interest.

\section{REFERENCES}

1. Jamshidi F, Nazari I, Malayeri HT, et al. Pattern of drug abuse in addicts self-referred drug rehabilitation centers in Khuzestan province Iran, 2014-2015. Archiwum Medycyny Sądowej i Kryminologii 2016; 66: 1-12.

2. Burghardt LC, Ayers JW, Brownstein JS, et al. Adult prescription drug use and pediatric medication expo-sures and poisonings. Pediatrics 2013; 132: 18-27.

3. Al-Jahdali H, Al-Johani A, Al-Hakawi A, et al. Pattern and risk factors for intentional drug overdose in Saudi Arabia. Can J Psychiatry 2004; 49: 331-334.

4. Al-Jahdali H, Al-Johani A, Al-Hakawi A, et al. Pattern and risk factors for intentional drug overdose in Saudi Arabia. Can J Psychiatry 2004; 49: 331-334.

5. Jalali N, Abdollahi M, Sharifzadeh M, et al. Mortality and morbidity of poisoning due to opium and its derivatives at Loghman Hakim Hospital Poison Center, 1994. Pejouhandeh Quarterly Research Journal 1997; 4: 9-17.

6. Flanagan RJ, Rooney C, Griffiths C. Fatal poisoning in childhood, England and Wales 1968-2000. Forensic Sci Int 2005; 148: 121-129.

7. Kadivar M, Javadinia N, Nemati N. A Survey on opium and its derivatives poisoning in children's hospital medical center. Journal of Medical Council of I.R.I. Summer 2000; 18: 100-106.

8. Moghadamnia AA, Abdollahi M. An epidemiological study of poisoning in northern Islamic Republic of Iran. East Mediterr Health J 2002; 8: 88-94.

9. Sachdeva DK, Stadnyk JM. Are one or two dangerous? Opioid exposure in toddlers. J Emerg Med. 2005; 29: 77-84.

10. Imran M, Uppal TB. Opium administration to infants in Peshawar region of Pakistan. Bull Narc 1979; 31: 69-75.

11. Haddad M, Shannon W, Winchester F. Clinical management of poisoning and drug overdose. WB Saunders, Philadelphia 2007; 640-647.
12. Shadnia SH, Esmaily H, Sasanian GH, et al. Pattern of acute poisoning in Tehran-Iran. Hum Exp Toxicol 2007; 26: 753.

13. Nagi N, Abdulallah Z. Kerosene poisoning in children in Iraq. Postgrad Med J 1995; 71: 419-422.

14. Budhathoki S, Poudel P, Shah D, et al. Clinical profile and outcome of children presenting with poisoning or intoxication: a hospital based study. Med Coll J 2009; 11: 170-175.

15. Bentur Y, Desiatnic Obchinikov N, Cahana A, et al. Pediatric Poisonings in Israel: National Poison Center Data. Isr Med Assoc J 2010; 12: 554-559.

16. Marcdante KJ. Poisoning. In: Kliegmen RM, Macdante KJ, Jenson HB. Nelson Essentials of Pediatrics. WB Saunders, Philadelphia 2006.

17. Hoffman RJ, Osterhoudt KC. Evaluation and management of pediatric poisonings. Pediatric Case Reviews 2002; 2: 51-63.

18. Kiani M, Shamloo B, Sadeghi A. Prevention from psychotropic drug abuse by audiences. Medical Rights Journal 2011; 19: 127-173.

19. Sadjadi M, Shariati N, Abbasnejad A, et al. Knowledge and attitude of students of about Gonabad University to psychotropic drug abuse. Ofoghe Danesh Journal. Gonabad University of Medical Sciences. 2009; 15: 58-65.

20. Vakili M, Momeni Z, Mohammadi M, Koohgardi M. Epidemiological study of accidents in children under 6 years of Azadshahr Yazd in 2011. PSJ. 2016; 14: 49-57.

21. Peden M, Oyegbite K, Ozanne-Smith J, et al. World Report on Child Injury Prevention. Geneva: Worldb Health Organization; 2008.

22. Mansouri K, Soori H, Farnaghi F, Khodakarim S. Evaluation of risk factors for unintentional toxication in children: A case-control study in Tehran. Safety Promotion and Injury Prevention. 2004; 1: 183-189.

23. Besharat S, Besharat M, Akhavan Masouleh A, et al. Opium intoxication in children under years old, Golestan-Iran (2010-2012). J Gorgan Uni Med Sci 2010; 12: 85-89.

24. Nikvarz M, Faramarzpour M, Vazirinasab H, Mozaffari N. The frequency of causes of poisoning in children referred to Imam Khomeini hospital of Jiroft in 2015. J Jiroft Univ Med Sci 2017; 3: 55-64.

25. Alotaibi N, Sammons H, Choonara I. Methadone toxicity in children. Arch Dis Child 2012; 97 (1).

26. Watson WA, Steele MT, Muelleman RL, et al. Opioid toxicity recurrence after an initial response to naloxone. J Toxicol Clin Toxicol 1998; 36: 11-17.

27. Sachdeva DK, Stadnyk JM. Are one or two dangerous? Opioid exposure in toddlers. J Emerg Med 2005; 29: 77-84.

28. Allameh Y, Akrami FS, Mohammadi G, Molavi N, Babakhanian M. Methadone Poisoning in Children: A Systematic Review and MetaAnalysis in Iran. J Pediatr Rev 2017; 5: 1-8.

29. LoVecchio F, Pizon A, Riley B, et al. Onset of symptoms after methadone overdose. Am J Emerg Med 2007; 25: 57-59. 